\title{
Ode to the Anesthesiologist Profectus
}

\author{
Rohan Magoon ${ }^{1,2} \quad$ ItiShri ${ }^{1,2}$ \\ ${ }^{1}$ Department of Cardiac Anaesthesia, Atal Bihari Vajpayee Institute \\ of Medical Sciences (ABVIMS), New Delhi, India \\ ${ }^{2}$ Dr. Ram Manohar Lohia Hospital, Baba Kharak Singh Marg, \\ New Delhi, India
}

\begin{abstract}
Address for correspondence Dr. ItiShri, MD, Associate Professor, Department of Cardiac Anaesthesia, Atal Bihari Vajpayee Institute of Medical Sciences (ABVIMS) and Dr. Ram Manohar Lohia Hospital, Baba Kharak Singh Marg, New Delhi 110001, India (e-mail: iti.anesthesia@gmail.com).
\end{abstract}

\begin{abstract}
Keywords

- anesthesiologist

- corona warrior

- tribute

As the Corona pandemic continues to challenge the medical fraternity, the anesthesiologists have emerged as an integral part of the system, right from elucidating the pathophysiology of the Coronavirus to the treatment and resilience in the face of all the challenges thrown. This personal perspective is a tribute to the anesthesiologist's progress from behind the scenes to an epidemiologist, intensivist, and Corona warrior.
\end{abstract}

We walk the aisle in celebration of winning our prolific race And mark our tradition of ingenuity and grace.

On the podium stands WTG Morton with ether,

Showcasing his legacy, "the Anesthesiologist Corona warrior." From equipment to epidemiology,

Challenging pandemic is in the roots of Anesthesiology.

1854: John Snow pioneers contact tracing,

That helps wane the caseload of the dreaded COVID-19.

Jerome Adams rises to be the Surgeon General,

Publicizes "COVID stops with me" slogan.

William New invents oximeter dynamics,

And Severinghaus elucidates blood gas analysis,

Diagnoses COVID-19 happy hypoxemia,

Titrating the oxygen therapy panacea.

Homage to Arthur Guedel for paving our way,

To positive pressure ventilation, keeping fears at bay.

Subduing corona with wisdom of cardiopulmonary interaction,

We stand high as intensivist beyond question.

Adhering to evidence-based approach amid the pandemics,

Patronage social distancing and question HCQ's benefits.

As SARS pandemic set the exemplar,

Innovative airway management wages the war.

published online

January 22, 2021
DOI https://doi.org/

$10.1055 / s-0041-1723624$

ISSN 2457-0206.
As MERS and Ebola ravaged the world,

Anesthesiologist ameliorates PPE and ICU infrastructure.

No matter how much COVID sets up a hard yard,

Anesthesiologists emerge as strategist, and erudite wizard.

Enterprising a multidisciplinary alliance,

Being a pillar of medicine and envisaging reforms.

We are physicians with nerves of steel,

With a gumption to keep stress and anxiety concealed.

Whilst COVID-19 challenges our skills and endurance,

Anesthesiologist has claimed "the hero" status.

We have evolved from the designation gasmen,

And graduated summa cum laude to the Times cover.

As achievements and milestones syndicate,

This World Anaesthesia Day, we have tributes to pay,

To the stalwarts and "heroes" who inspire us every which way,

Gathering grit in the battle against the current viral rage.

\section{Conflicts of Interest}

The authors declare no competing interests.

Support was provided solely by institutional and/or departmental sources.

\footnotetext{
(c) 2021. Official Publication of The Simulation Society (TSS), accredited by International Society of Cardiovascular Ultrasound (ISCU).

This is an open access article published by Thieme under the terms of the Creative Commons Attribution-NonDerivative-NonCommercial-License, permitting copying and reproduction so long as the original work is given appropriate credit. Contents may not be used for commercial purposes, or adapted, remixed, transformed or built upon. (https://creativecommons.org/licenses/by-nc-nd/4.0/) Thieme Medical and Scientific Publishers Pvt. Ltd., A-12, 2nd Floor, Sector 2, Noida-201301 UP, India
} 